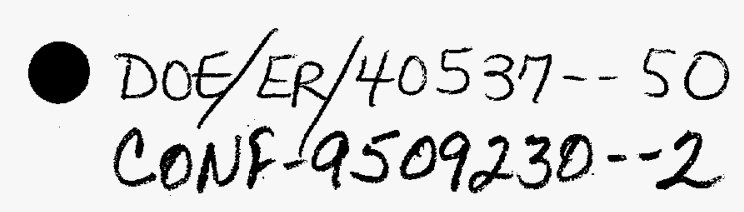

\title{
Terminal Ion Source for an FN Tandem
}

\author{
G. C. Harper \\ Nuclear Physics Laboratory, GL-10, University of Washington, Seattle, WA 98195
}

\begin{abstract}
An RF discharge source assembly has been developed for use in the terminal of the FN tandem van de Graaff accelerator at the Nuclear Physics Laboratory of the University of Washington. The primary motivation for developing the source was to provide a high intensity beam of ${ }^{3} \mathrm{He}^{+}$to produce ${ }^{8} \mathrm{~B}$ from the reaction ${ }^{6} \mathrm{Li}\left({ }^{3} \mathrm{He}, \mathrm{n}\right)^{8} \mathrm{~B}$. The design of the optics and the performance of the source are described here.
\end{abstract}

\section{Description}

An RF discharge source assembly has been designed and developed for use in the terminal of an FN tandem van de Graaff accelerator to produce a high intensity, low energy beam of ${ }^{3} \mathrm{He}^{+}$. The assembly illustrated in fig. (1) consists of a commercially manufactured $\mathrm{RF}$ discharge source [1] a flanged, porcelain insulator containing an extractor electrode and einzel lens, a double focussing permanent dipole magnet, vertical and horizontal electrostatic steerers, and a moveable faraday flap.

The RF source was specified to deliver $400 \mu$ amps of ${ }^{1} \mathrm{H}^{+}$from a $2 \mathrm{~mm}$ diameter aluminum canal while producing a gas load of 1-2 mTorr-l/sec. Since the tandem does not have any terminal pumping, a large gas load was expected to result in collisions with the low energy particles. In order to reduce the gas load, a $1 \mathrm{~mm}$ diameter canal was specified. Helium throughput at the high energy end of the tandem was increased by replacing a cryopump at that location with a turbomolecular pump. Output current from an RF discharge source varies as $(d / l)^{2},[2]$ where $d$ is the canal diameter and $l$ is the length, and as $1 / \sqrt{m}$, where $m$ is the mass in AMU, according to the manufacturer. The gas load varies approximately as $d^{3} / l$. $[3,4]$

The extraction insulator is a $7.5 \mathrm{~cm}$ long $10 \mathrm{~cm}$ ID tube of glazed porcelain. The tube is epoxied at one end to a flange that mates with the RF source and epoxied at the other end to a flange on a $7 \mathrm{~cm}$ nipple. On the other 


\section{DISCLAIMER}

Portions of this document may be illegible in electronic image products. Images are produced from the best available original document. 


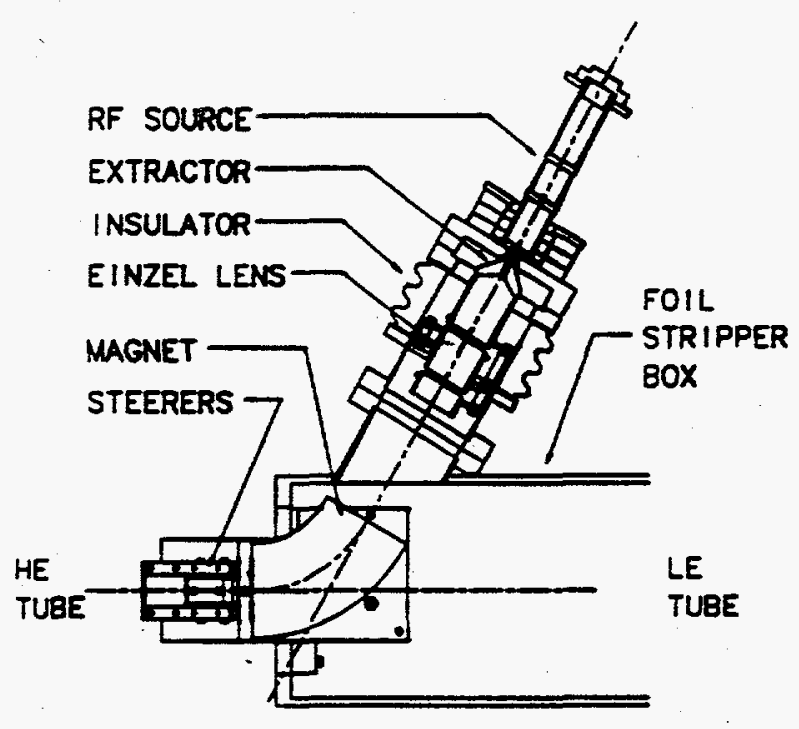

Fig. 1. Layout of the RF discharge source and optics

end of the nipple is a standard 6 inch conflat flange. The extractor electrode and the ground electrodes of the einzel lens are connected to weldments on the nipple, and a high voltage feedthrough permits connection to the center electrode of the einzel. The insulator assembly is mounted on the foil-stripper drive assembly port on the stripper box in the terminal of the tandem. The port is $60^{\circ}$ off of the beam axis.

The permanent, dipole magnet has bending radius, $R$, of $14 \mathrm{~cm}$ and bending angle $60^{\circ}$ to transport the beam onto the accelerator axis. The poles are made from $8 \mathrm{C}$ ferrite material with the pole faces cut at $17^{\circ}$ to the beam axes to produce double foci at $3.46 \mathrm{R}$, [5] or about $50 \mathrm{~cm}$ from the pole faces. The frame is made from soft steel. The entire assembly is magnetized to produce a transverse B-field of $2.5 \mathrm{kG}$. The poles are epoxied onto the top and bottom frame pieces. Thin $(1.5 \mathrm{~mm}$ ) steet pole tips which overlap the poles by $3 \mathrm{~mm}$ on each side along the beam trajectory reduce the field to $1.9 \mathrm{kG}$ and make the fringe fields at the pole faces more uniform to improve focussing. The magnet is mounted on a platform inside the foil-stripper box.

Vertical and horizontal steering plates are mounted on the platform downstream from the magnet. The plates are $5.7 \mathrm{~cm}$ wide, $4.5 \mathrm{~cm}$ long and spaced $2.6 \mathrm{~cm}$ with the horizontal pair preceding the vertical pair by $3 \mathrm{~mm}$. Bipolar power supplies producing $\pm 700 \mathrm{~V}$ drive the steering plates.

In order to measure the source output before accelerating the beam, a $2.5 \mathrm{~cm}$ diameter faraday flap is inserted between the magnet and the horizontal steering plates. The fringe fields from the magnet effectively suppress secondary electron emission from the flap. The flap is removed by a motor-driven, bellows-sealed actuator. 


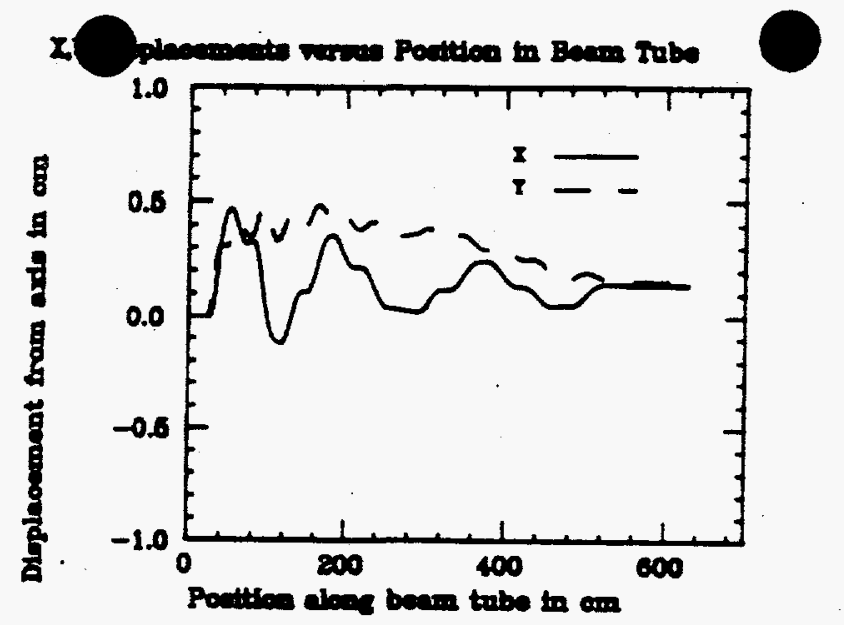

Fig. 2. Variations in the vertical and horizontal displacements of the ion beam along the axis of the spiral inclined field tube at $3.0 \mathrm{MV}$ terminal voltage. $Y$ displacement is the dashed line, $X$ is solid.

\section{Modification of the beam tube gradient}

The entrance voltage gradient of the spiral inclined fieid tube constitutes much too strong a lens for the low energy $(17 \mathrm{keV})$ beam and the transverse electric field components are large enough to sweep the beam into the side of the tube. The gradient of approximately the first quarter of the accelerator tube is reduced during source operation to alleviate these problems. Twenty two resistor assemblies having $20 \%$ of the nominal column resistor value are installed at the entrance to the tube. These are followed by 3 assemblies with $50 \%$ value, 10 assemblies with $60 \%$ value and 14 assemblies with $70 \%$ value. A plot of the calculated vertical and horizontal displacements of the beam versus distance along the tube is given in fig. (2).

\section{Preliminary Tests}

Preliminary bench tests of the source revealed some problems. The probe voltage, which defines the plasma potential, was optimal at $1.8 \mathrm{kV}$ which is subetantially less than the $6 \mathrm{kV}$ expected. As a resuit, a beam waist was formed between the extractor and the einzel lens where a diverging envelope had been expected. This effectively moved the object point for the lens from $30 \mathrm{~cm}$ to $10 \mathrm{~cm}$ and required operating the lens at a much higher voltage than desired. In fact, the extractor voltage had to be reduced $2 \mathrm{kV}$ in order to produce a low enough energy to focus the beam at all.

Only $10 \%$ of the beam was transported through the magnet assembly. The shape of the beam was very irregular having what appeared to be a 3-fold symmetry with odd lobes. The size of the beam spot was $1.0-1.5 \mathrm{~cm}$ at the magnet exit and it was strongly divergent where it should have been con- 


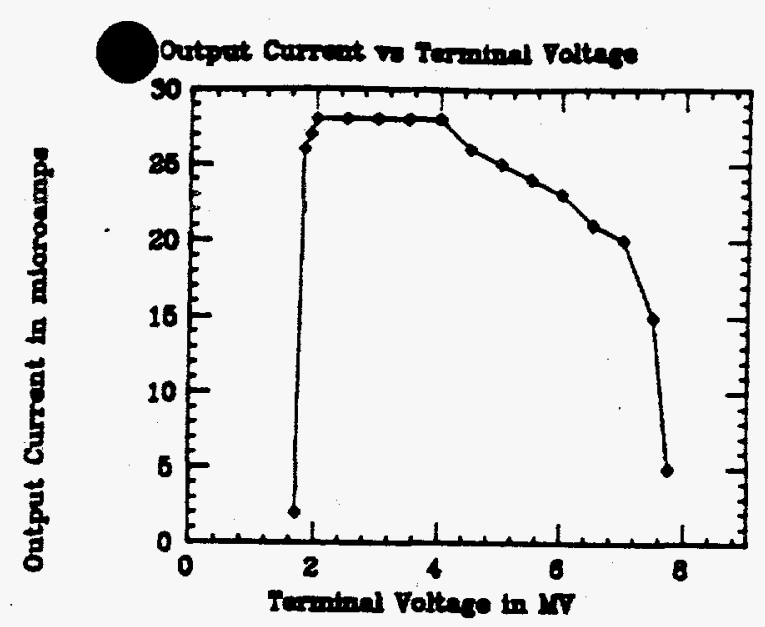

Fig. 3. Transmission of the ${ }^{3} \mathrm{He}$ beam as a function of terminal voltage

verging. Careful measurement indicated that the vertical component of the fringe field was extremely irregular. It was determined that the $8 \mathrm{C}$ material, although an excellent permanent magnet, has a very low relative permeability and is unable to produce uniform fields in the fringe regions. Pole faces of soft steel with high permeability were attached to the $8 \mathrm{C}$ poles. The edge was beveled by $45^{\circ}$ to avoid saturation of the steel in that region. This produced beam profile, intensity and diameter as originally expected.

During the initial tests, the gas load produced by the source was a factor of 10 higher than that specified by the manufacturer and the beam current was a factor of 10 lower. Experimentation with the layout of the flying leads carrying RF power to the source and with the position of the capacitive coupling clamps on the source bottle improved the performance a great deal. The coupling of RF power into the plasma can be altered dramatically by small changes in positioning. Improved RF coupling apparently increases the plasma density and, consequently, the source output current rises even with a reduction in the gas flow.

\section{Performance}

Beam current was expected to be $58 \mu$ amps with a gas load of $0.2 \mathrm{mTorr}-1 / \mathrm{sec}$. The source produces 32 ramps of analyzed beam with a measured gas load of $0.76 \mathrm{mTorr}-1 / \mathrm{sec}$ and a focussed FWHM of $1.3 \mathrm{~mm}$. The beam emittance measured is $1.1 \pi \mathrm{mm} \operatorname{mrad} \sqrt{\mathrm{MeV}}$. At the $5.5 \mathrm{MV}$ terminal voltage required by the experiment, $90 \%$ of the beam is transported through the spiral inclined field tubes. In the terminal voltage range of $1.8 \mathrm{MV}$ to $7.5 \mathrm{MV}$ over $50 \%$ of the beam is transported as shown in fig. (3). The source ran uninterrupted

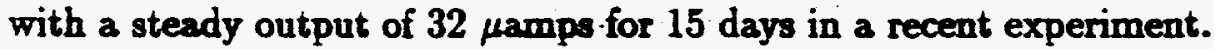




\section{References}

[1] National Electrostatics Corporation, Middleton, WI, USA.

[2] K.R. Spangenberg, Vacuum Tubes (McGraw-Hill, 1949) 447.

[3] V.J. Kowalewski, C.A. Mayans, and M. Hammerschlag, On some properties of the radio frequency ion source with longitudinal magnetic field, Nuclear Intruments and Methods bf 5 (1959) 94.

[4] S.K. Allison and E. Norbeck, Simplified radio-frequency ion source, Review of Scientific Instruments 275 (1956) 287.

[5] J.J. Livingood, The Optics of Dipole Magnets (Academic Press, 1969) 63.

\section{DISCLAIMER}

This report was prepared as an account of work sponsored by an agency of the United States Government. Neither the United States Government nor any agency thereof, nor any of their employees, makes any warranty, express or implied, or assumes any legal liability or responsibility for the accuracy, completeness, or usefulness of any information, apparatus, product, or process disclosed, or represents that its use would not infringe privately owned rights. Reference herein to any specific commercial product, process, or service by trade name, trademark, manufacturer, or otherwise does not necessarily constitute or imply its endorsement, recommendation, or favoring by the United States Government or any agency thereof. The views and opinions of authors expressed herein do not necessarily state or reflect those of the United States Government or any agency thereof. 